tion. We must get closer to the people in general and do more missionary work from house to house.

We must discourage the constant tendency of suggestions to young girls and women about the menstrual function. We must teach that this physiologic process in a healthy body will be taken care of by nature without artificial assistance.

We must see to it that the young woman has a sound body if she wants to acquire knowledge; that it is more important to have a healthy body than to possess great learning. We must oppose the cry that too much is being taught in our higher schools or the universities, that the demand on the mind is too great, as that is entirely wrong. We must teach that everybody was not born to attain this higher education, that only those should attend the higher institutes of learning who have the attributes of the mind which enable them to learn easily and quickly, and that even these require plenty of exercise and fresh air.

We should insist that gymnastics and systematic physical exercise should be taught in every school of the land, from the lower to the highest, and that the curriculum of study should embrace the most systematic course of gymnastics to produce a sound body with a sound mind.

We should thoroughly study the effects and the results of erotism on the human body. We should study how we can more thoroughly bring about a more perfect marriage relationship and prevent the frequent mismating, as shown in our courts.

In fact, we must more thoroughly study the exact positions of individuals, every combination of physical and mental condition and their most fit place and most proper vocation in life. We must branch out, we must look ahead, we must be the counsellors and the guides of the race in the future.

\section{PHYSICAL DIAGNOSIS AS RELATED TO DENTAL COLLEGE CURRICULA.}

CHAIRMAN'S ADDRESS, DELIVERED BEFORE THE SECTION ON STOMATOLOGY, AT THE FIFTY-THIRD ANNUAL MEETING OF THE AMERICAN MEDICAL ASSOCIATION AT SARATOGA SPRINGS, N. Y., JUNE 10-13, 1902.

A. H. PECK, M.D., D.D.S. CHICAGO.

In view of the fact that during the past two years a number of the state boards of dental examiners throughout the country have added the subject of physical diagnosis to their list of studies, which must be passed to secure a license to practice dentistry in their respective states; also, that I have for some years been impressed with the desirability and, I may say, the necessity, of adding this subject to our dental college curricula, I concluded this would be as fit a subject as any for my paper at this time.

Heretofore this subject, whenever taught at all, has received what 1 may term unconscious attention from various teachers; that is to say, in the regular teaching of their departments they have naturally referred to phases of physical diagnosis, but not until the past year has the subject been made a separate department and a complete course of instruction given.

The knowledge of man has steadily increased. keeping apace with civilization. Man has been brought to a higher plane through scientific investigation; his mind broadened and ripened in the fields of research. The furtherance of their profession and the elevation of their fellow-men have ever been uppermost in the minds of the great men of the past.
As you are familiar, it was discovered ages and ages ago that teeth were filled with pieces of wood, ivory and other materials, as evidenced by the researches of the catacombs of Rome and Naples, thus assuring us that the art of preserving teeth was known to our ancestors of those very early times. Unfortunately, however, we do not know who the great dentists of those ages were, as the records of this work have been lost. Had this work been entirely satisfactory to these dentists and their patients, the latter being pleased and contented with such operations, our profession would never have attained to its present high, enviable position in this professional world.

Dissatisfaction with prevailing methods, and the laudable desire to excel, set men to thinking and to doing, the result being that dentistry has developed from a humble trade to an honored profession, affording a field for usefulness to thousands and whereby the suffering of the entire civilized world can be and is, in a great measure, alleviated.

During the past few years the courses of study have been lengthened in all professional schools. Only a short time has elapsed since a medical student could graduate after attending two courses of instruction of six months each, but now one is required to attend four years of nine months each, after having gained a good scientific or classical education as a foundation upon which to build his professional knowledge, thus requiring from six to eight years of college work to receive his degree of doctor of medicine. Let us not forget that dentistry has by no means been slumbering all the while, for the educational requirements for admission to a dental college have been steadily advancing, and the number of years and length of terms increasing, unitil now schooling equal to the second year of high-school work is required. and in another year four years of seven months each will be required.

Only a few years ago a student received a few lectures on physiologv, when that part of his course was considered finished, but now it is one of the most important branches he has. Histology, pathology and bacteriology have become important subjects, and the dentist would also be considered verv lame without a knowledge of anesthesia and oral surgery. More than this, the amount of practical work that must be done as a part of the dentist's preliminary education has more than doubled. What is the object of this advance? It is that his knowledge may be broadened, extended and that he may be placed on a higher plane with mankind, as well as that he may be better able to satisfy himself and his patients after engaging in the practice of his chosen profession.

We, as professional men, are continually being called upon to give opinion as to the etiology and prognosis of certain diseases, and who will attempt to gainsay the statement that this we should be not only willing but able to. do. and it is imperative that we be as nearly correct in such counsel as possible. At times we find this easy, and again it taxes us to the limit, if not beyond; all our knowledge and reason is called into play before we are able to make definite statements.

It is not always an easy matter to tell just how much vitality a patient has, nor how much of a nervous shock one can endure, nor how long one can remain in a dental chair at a sitting without sustaining material injury. This we, as dentists, should know, so that our patients, on leaving our offices, will have received professional benefit instead of injury.

Who of you have not seen or are not cognizant of neurotic patients who were nervous wrecks for days after 
having had a large amount of dental work done? With the requisite knowledge and the exercise of forethought and judgment, all this can be avoided. A few more sittings of shorter duration would have completed the work, at the same time acting as a stimulus rather than a nervous shock. This knowledge we can gain only by a thorough study of our patients, and an understanding of the cause or causes of their ailments.

I hope to see the time when a dentist will inquire into the health and symptoms of his patients before deciding on the amount of work that is proper and safe to be done at any one sitting, as should a physician before prescribing a certain amount of a drug or drugs that are to be given for an ailment of the patient.

To judiciously outline our work we, as dentists, must have as thorough a knowledge as possible of the various diseases of mankind, especially those affecting the vital organs or those organs most likely to suffer when shock is inflicted. The symptoms of these diseases, also the physiologic changes that may occur, are necessary to be understood. Who of us would keep a patient, afflicted with organic heart disease, in our chair for an unusually long and fatiguing operation if we be able to inform ourselves of the true condition of these parts.

There is only one way for us to gain this knowledge, and that is for us to familiarize ourselves with the normal heart, as to location, size, beat, rhythm and sounds, thus enabling us to recognize pathologic conditions when present. How embarrassing it must be for any dentist, after advising the administration of a general or local anesthetic, to be told, on consulting the family physician, that such a course would mean certain death to the patient, whether true or not.

Physical diagnosis is the term used to designate those methods which are employed in the detection of disease during life by the anatomic changes produced by it. The nature and extent of such changes can only be recognized and appreciated by the divergence which they cause in the affected organs from the known physical condition of these organs when in health.

The significance of physical signs in disease cannot be determined by theory; only by clinical observation confirmed by observation after death can this significance be determined.

If it be granted that it is at all desirable that the dentist shall possess this knowledge I am talking about, it at once becomes evident that he must enter into a systematic and thorough study of the only methods by which these physical signs can be determined in the living subject, and these methods are: 1, Inspection; 2 , palpation; 3 , mensuration: 4 , percussion ; 5 , auscultation; 6 , radioscopy.

Some of these methods have been in use for many centuries. Palpation, for instance, was used in the Neolithic or polished stone age, $1500 \mathrm{~B}$. C., to demonstrate the presence of fluctuation, while radioscopy is practically new. This method is the outcome of the discovery of the X-rav, by which, with the use of the fluoroscope, tumors or solid bodies are located in various parts of the body. that were impossible of discovery before. Fractures of bones, the exact kind and position, are determined by looking at the bone direct. Tumors of the internal organs are observed by this means, thus enabling one to diagnose conditions which were impossible of discovery before the $x$-ray was in use.

One must also be conversant with the various areas into which the body is divided, and which are bounded by definite anatomic relations. This is necessary that one, being familiar with the normal size and location of an organ, can determine whether it is in its proper position.

It is necessary to know that the first area from a physiologic standpoint is the supra-clavicular region; and that this area is definitely bounded below by the inner three-fifths of the clavicle, internally by the trachea, and superiorly by a line extending from the junction of the onter with the middle third of the clavicle to the top of the trachea. Also, it is necessary to know that normally within this area are to be found the apex of the lung, the carotid artery, the subclavian artery, the subclavian vein and the jugular vein.

Next below this is the clavicular region, which is that part of the thoracic cavity lying back of the inner threefifths of the clavicle. An understanding of the anatomic boundaries and contents of this region is also necessary, but with which I shall not inflict you in this paper.

The most important regions, from the standpoint of the dental practitioner, are the following: Infra-clavicular, the boundaries of which must be carefully studied, that one may recognize the presence of the vital anatomic structures and organs in their normal positions. In this region are to be found, on the right side, lung tissue, the ascending vena cava. the right bronchial tube lying back of the sterno-costal articulation and also a small portion of the arch of the aorta. On the left side are found the pulmonary artery from its origin to its bifurcation. the left bronchial tube lying a little below the second sterno-costal articulation.

The next region of special importance to the dentist, and which lies immediately below the preceding one, is called the mammary region.

The lowest region in the anterior aspect of the thoracic cavity is called the inferior mammary.

Centrally located is the sternum, this area being divided into three regions: (1) The supra-sternal; (2) the upper sternal, and (3) the lower sternal.

The back is divided into three regions: (1) The supra-scapular; (2) the infra-scapular, and (3) the inter-scapular.

All these regions should be carefully studied, as indicated above, in the two instances in which the boundaries and contents are stated.

A knowledge of the size and exact location of the heart is especially important. In the average subject the base of this organ is found at the sccond intercostal space, the apex beat or the maximum impulse being at the fifth intercostal space. from three-fourths to an inch to the left of the sternum. It must be understood that the apex bcat does not locate the apex of the heart, the latter being about an inch to the left of the beat.

The anatomy of the heart must be studied. It is necessary to know that there are four different valves, and what is expected of them in the performance of their normal function, and that the positions on the chest where the sounds made by the valves can be most distinctly heard are not immediately over the organ.

I thus briefly outline this foundation work that there may be no mistake as to what I consider necessary in the schooling of prospective dentists, that they may be able intelligently to apply the six methods of eliciting the physical signs of the various pathologic conditions of those diseased organs bearing directly on the practice of dentistry.

It is also necessary to be thoroughly conversant with the meaning of these various methods of physical diagnosis, how each is to be employed, and what is to be learned by it; that inspection means only that which can be determined by looking at the patient without further means of diagnosis; that palpation means the examina- 
tion of the parts by the laying on of the hands, and in this method only the tips of the fingers may be used, or the palms of the hands as a whole; that with mensuration certain facts are to be determined by the process of measuring; that by percussion is meant the tapping of the chest to elicit certain sounds under the varying conditions; that there are different methods of percussion, the immediate and the mediate; that auscultation is the act of listening for sounds within the body, chiefly to ascertain the condition of the lungs, heart, pleura and other organs; that there are different methods of: auscultation, the immediate, which is the application of the ear directly to the part, and the mediate, which is by use of the stethoscope. The pulse is such an accurate index to many of the lesions of the heart, it is necessary that one shall understand it in all its variations.

'Thus would I have dental students instructed. I trust this paper will receive full and unrestricted discussion, for $I$ want to know whether, in your judgment, this branch should be added to the curriculum of our dental institutions of learning.

This is a subject that has engaged my attention for some time, and it was my desire more than two years ago to present this subject to the profession and urge its teaching in our schools, but listening to the advice of trusted friends that the time was not ripe for it I desisted. During the past year it has been taught in the institution with which I am connected.

As I see it now, I cannot understand how anyone can advise otherwise.

I hope to see prospective dentists so instructed in the future that they shall be able to recognize diseased conditions of at least these vital organs, and thus be enabled to avoid serious and possibly fatal mistakes. When this knowledge is acquired and successfully practiced, the dentist at once gains the implicit confidence of his patients, his word with them becomes law, and his opinion is sought and respected. Such a dentist is a real benefactor in the community in which he resides and his success is assured.

He also has the satisfaction of knowing he is one who has participated in that "higher education." the practice of which can only result in assisting to elevate the standard of his profession, and to place it on a higher plane in its relation to other progressive professions.

\section{THE EMBRYOLOGY OF THE DENTAL PULP.*}

\section{R. R. ANDREWS, A.M., D.D.S. CAMBRIDGE, MASS.}

At the invitation of the secretary of our section to present a paper on some subject connected with the dental pulp, I shall consider at this time the dental pulp in its embryologic aspect. Such an aspect appeals to me the more strongly from the fact that I have given special attention in earlier research work to dental embryology. In a general way. I shall consider the growth of the dentine germ from the earliest signs of its development, the formation of the dentine from the germ, and lastly, the fully formed and functionally mature pulp. This subject may not offer anything that is particularly new, but there are several points that I have recently been trying to clear up, and a discussion of them may prove of general interest to the Section on Stomatoloov.

At about the end of the second and the beginning of the third month of intra-uterine life, in the embryonic

* Read at the Fifty-third Annual Meeting of the American Medical Association. in the Section on Stomatology, and approved for publication by the Executive Committee. tissue of the jaw, we shall find the primary specialization of cells which are to form the dentine germ. and from which come the cells which afterwards form the dental pulp. It is in no special zone or layer of this connective tissue that the dental germ is formed, but the formation seems wholly influenced by the contact with an enamel organ. In the presence of this organ, the connective tissue cells become stimulated and active. It would appear as though they offered a resistance to its further growth, and from this resistance the enamel organ was made to expand, thus becoming flattened and broadened. The stimulation and activity of the cells is shown by their rapid growth, which clouds the part at this point, becoming a dense focus of new growth. The tissue is seen to be actively building itself up, and this results in the formation of a papilla, around which the enamel organ is growing like a cap or helmet. This process of new growth is a beautiful illustration of anabolic metabolism. The papilla grows to a cusp or cusps; and now becomes the dentine germ. At the end of the third and at the beginning of the fourth month, the dentine germ is rather a homogeneous structure. Round cells are very numerous; they have relatively large nuclei and nucleoli. As the germ assumes the cusp shape, multiplication of cells takes place around the blood vessels, which have grown into the base of the germ, and a jelly-like laver has formed around its outer surface. It will be found that the dental germ will grow into the depressions of the enamel organ of a bicuspid or molar tooth, and these growths will become the dentine cusps. We also notice that the different layers of the enamel organ are now formed, and that the sacullus is now forming its layers about both enamel organ and dentine germ. When this process is completed, these are enclosed in a sac, and thus become a dental follicle. Within the area of the dentine germ are contained all of the cells which shall develop later into the mature dentine, and into the pulp of the fully-formed tooth.

The round cells around the rim of the dentine papilla appear to be in a protoplasmic substance, sometimes called a zone of amorphous material. It is a hyalin structure on the outermost surface of the germ. The cells just within become richer in protoplasm, and many processes are seen to be forming from them. They are becoming branched cells, a little later the cells at the surface grow larger and assume a columnar shape which may be caused by mechanical compression. We also see just within this layer of cells some that are pear-shaped, conical, cylindrical, and spindle-shaped. There are some authorities who have spoken of what they call elementary cells on the outer layers, and from which they say the odontoblasts are formed, but I have never observed anything but globular masses that are not cells, and which are found in the protoplasmic substance of the rim spoken of above. At the beginning of the fifth month these cells on the surface are seen to be undergoing a histologic differentiation, as stated above, and are becoming specialized or formative cells, the odontoblasts. They are membraneless and little more than masses of protoplasm, which are seen to be filled with great numbers of bright, glistening globules of different sizes. The so-called "conjugation cells" of the German authorities are what I believe to be the pear-shaped fiber-forming cells. These are seen to be sending their processes into the intercellular spaces of the odontoblasts, and thus I believe the fiber to be formed. At this time dentinification is about to begin. How does this process of calcification take place? This 